\title{
Association of nutritional status-related indices and chemotherapy-induced adverse events in gastric cancer patients
}

Seung Hee Seo ${ }^{1,3 \dagger}$, Sung-Eun Kim ${ }^{1 \dagger}$, Yoon-Koo Kang², Baek-Yeol Ryoo ${ }^{2}$, Min-Hee Ryu ${ }^{2}$, Jae Ho Jeong ${ }^{2}$, Shin Sook Kang ${ }^{3}$, Mihi Yang ${ }^{4}$, Jung Eun Lee ${ }^{1}$ and Mi-Kyung Sung ${ }^{1 *}$

\begin{abstract}
Background: Malnutrition in gastrectomized patients receiving chemotherapy is associated with the susceptibility to chemotherapy-related adverse events. This study evaluated pre-operative nutritional status-related indices associated with adverse events in post-operation gastric cancer patients receiving chemotherapy.

Methods: Medical records of 234 gastrectomized patients under adjuvant tegafur/gimeracil/oteracil chemotherapy with extended lymph node dissection were analyzed. Nutritional status assessment included Patient-Generated Subjective Global Assessment (PG-SGA), body weight, body mass index, serum albumin concentration, and Nutrition Risk Index (NRI). Chemotherapy-originated adverse events were determined using Common Terminology Criteria for Adverse Events.

Results: PG-SGA indicated $59 \%$ of the patients were malnourished, and $27.8 \%$ of the patients revealed serious malnutrition with PG-SGA score of $\geq 9$. Fifteen $\%$ of patients lost $\geq 10 \%$ of the initial body weight, $14.5 \%$ of the patients had hypoalbuminemia $(<3.5 \mathrm{~g} / \mathrm{dL})$, and $66.2 \%$ had NRI score less than 97.5 indicating moderate to severe malnutrition. Hematological adverse events were present in $94 \%$ ( $\geq$ grade 1 ) and $16.2 \%$ ( $\geq$ grade 3 ). Non-hematological adverse events occurred in $95.7 \%$ ( $\geq$ grade 1 ) and $16.7 \%$ ( $\geq$ grade 3 ) of the patients. PG-SGA and NRI score was not associated with treatment-induced adverse events. Multivariate analyses indicated that female, low body mass index, and hypoalbuminemia were independent risk factors for grade 3/4 hematological adverse events. Age was an independent risk factor for grade 3/4 non-hematological adverse events. Neutropenia was the most frequently occurring adverse event, and associated risk factors were female, total gastrectomy, and hypoalbuminemia.
\end{abstract}

Conclusions: Hypoalbuminemia, not PG-SGA or NRI may predict chemotherapy-induced adverse events in gastrectomized cancer patients.

Keywords: Gastric cancer, Malnutrition, Chemotherapy, Adverse events, Hypoalbuminemia

\section{Background}

Malnutrition in cancer patients originates from tumorinduced metabolic abnormalities and treatment-related side effects [1]. Previous studies suggested that $40-80 \%$ of cancer patients experience malnutrition which is also a major cause of cancer deaths [2, 3]. Gastrectomy followed by chemotherapy is the mainstay to treat gastric

\footnotetext{
* Correspondence: mksung@sm.ac.kr

${ }^{\dagger}$ Equal contributors

'Department of Food and Nutrition, Sookmyung Women's University, 100,

Cheongpa-ro 47-gil, Yongsan-gu, Seoul 04310, South Korea

Full list of author information is available at the end of the article
}

cancer, and majority of gastric cancer patients under treatment experiences malnutrition. Partial or full gastrectomy reduces food intake per serving and induces anastomosis and vagal block causing abdominal sense of distension, discomfort, and frequent bowel movement. Chemotherapy following gastrectomy also induces anorexia, sore throat, dry mouth, taste change, nausea, diarrhea, constipation, and fatigue which eventually lead to weight loss and malnutrition [4]. High risk of malnutrition among gastrectomy patients was shown to delay the rate of recovery and increase cancer deaths [5]. Malnutrition 
in cancer patients reduces responses to the treatment [6] and increases treatment-associated side effects [7] often lowering the intensity of treatment protocol and sometimes treatment withdrawal. Therefore, it is important to determine nutritional status of gastric cancer patients before starting chemotherapy to maximize the efficiency of treatment as well as the patients' quality of life.

Nutrition screening is an important step to identify cancer patients who are at risk for malnutrition and to provide information required for treatment protocol preparation. The Malnutrition Universal Screening Tool (MUST) scores are often used for surgical patients and have been validated for cancer patients [8]. However, the applicability and accuracy of MUST in assessing nutritional status of gastric cancer patients has not been well evidenced. Patient-Generated Subjective Global Assessment (PG-SGA) is the most frequently used nutritional assessment tool for cancer patients [9]. It is a comprehensive screening method comprised of weight loss, performance status scores, and clinical evaluation scores recommended for assessing malnutrition in surgical cancer patients. A number of studies have also suggested that serum albumin concentration is a mortality prognosis factor in cancer patients [10]. Nutrition Risk Index (NRI) is another tool to assess nutritional status of operated patients receiving parenteral nutrition using serum albumin and weight change [11].

The standardized treatment protocol for stage 2 or 3 stomach cancer is gastrectomy followed by adjuvant tegafur/gimeracil/oteracil (S-1) chemotherapy [12]. Although S-1 exhibits relatively mild side effects, it has been reported that the completion rate at 1 year after gastrectomy is 65.8 and $42.4 \%$ of the patients need dose modification mostly due to treatment-associated side effects [12]. Age over 65 and total gastrectomy have been suggested as risk factors associated with treatment-associated side effects in these patients [13]. In the present study, we identified baseline nutritional status-related indices most closely related to the chemotherapy-induced adverse events in stage 2 and 3 gastrectomy cancer patients.

\section{Methods}

\section{Study patients}

This is a retrospective study using medical records of the patients diagnosed as having stomach cancer from Asan Medical Center in Seoul, Korea between October, 2007 and December, 2009. A total of 305 patients were screened and those with stage 2 or $3 \mathrm{~A}$ stomach cancer according to the Guideline of the American Joint Committee on Cancer, and records of 234 gastrectomy patients ( $\geq 20$ years old) who underwent S-1 chemotherapy and who had 0 to 2 physical performance level based on the guideline of the Eastern Cooperative Oncology Group were included. S-1 chemotherapy was performed within 3 to 6 weeks after gastrectomy in most of the patients. Patients who had experience of cancer therapy, need different therapy protocols, had other types of diseases including liver diseases and kidney diseases, transferred to other hospitals, and had mental illness were excluded. The study was approved by the Institutional Review Board of Asan Medical Center (2012-0221).

\section{Treatment protocol and measurement of adverse events}

Treatment schedule of $\mathrm{S}-1$ is composed of a $40 \mathrm{mg}$ dosage $/ \mathrm{m}^{2}$ body surface area twice a day for 4 weeks followed by a 2 weeks of off period. Patients received a maximum of 8 cycles of S-1 treatment for a year. Once there are hematological adverse events ( $\geq$ grade 3 ) or non-hematological adverse events ( $\geq$ grade 2 ), the dosage was reduced by the discretion of the doctor. Treatment associated adverse events were determined and recorded by the guidelines of Common Terminology Criteria for Adverse Events (CTCAE, version 3) which are based on hematological tests, radiological examinations, and physical examinations. The score of each side effect was the highest score among measurements during the treatment period. Changes in drug dosage and suspension of ongoing therapy due to side effects were also recorded with respective reasons. Hematological examinations were performed before starting a cycle of 6 weeks treatment. Recurrence was determined the $2^{\text {nd }}$ or $3^{\text {rd }}$ abdominal CT and endoscopy at the end of the final treatment cycle.

\section{Clinical assessments}

Age, sex, tumor stage, height and weight, extent of surgery, medical history, treatment compliances, creatinine clearance, drug dosage, and existence of recurrence were examined prior to the first S-1 chemotherapy. It was reported that patients with kidney malfunction that fail to remove S-1 metabolites resulted in severe side effects [14].

\section{Nutritional assessments}

Scores of PG-SGA and NRI determined before starting the first cycle of chemotherapy were used. PG-SGA scores were composed of two sections of numerical scores. The first section was a medical history section completed by the patient, and the second section was a physical examination section completed by medical staff. The sum of scores were grouped as A $(<9$, mild or moderate malnutrition) and $B(\geq 9$, severe malnutrition). NRI was calculated as follows: $\mathrm{NRI}=(1.519 \times$ serum albumin, $\mathrm{g} / \mathrm{dL})+\{41.7 \times$ present weight $(\mathrm{kg}) /$ ideal body weight $(\mathrm{kg})\}$. Nutritional risk was defined as three grades: 1) major risk (NRI < 83.5); 2) moderate risk (NRI $83.5 \sim 97.5)$; 3) mild risk (NRI $97.5 \sim 100)$. Body weight change between admission and the start of first treatment cycle was calculated and Body Mass Index (BMI) was determined. 


\section{Statistical analyses}

Statistical analyses were performed using SPSS version 18.0 (Chicago, IL, USA). Demographical and clinical data were allocated into either continuous data or categorical data. Continuous data were expressed as means \pm standard deviations while categorical data were expressed as absolute or relative frequencies. Associations between adverse event and clinical or nutritional variables were analyzed by binary logistic regression analyses. Covariates used in each multivariate analysis were those which showed significance in univariate analysis.

\section{Results}

\section{Patient characteristics and dietary regimen}

Clinical characteristics of the patients are presented in Table 1. Study subjects were composed of 147 males and 87 females. The median age was 55 years old, and there were 38 patients who were over 65 years old. The number of stage 2 and 3A patients were 123 and 120, respectively. The number of patients who underwent total gastrectomy was 93, and the rest of the patients underwent partial gastrectomy. Patients were hospitalized for

Table 1 Characteristics of the patients

\begin{tabular}{ll}
\hline Characteristic & No $(\%)(n=234)$ \\
\hline Sex & $147(62.8)$ \\
Female & $87(37.2)$ \\
Age (yr) & \\
Median & 55 \\
Range & $25-78$ \\
Tumor stage & \\
T1 ${ }^{\text {a) }}$ & \\
T2a & $4(1.70)$ \\
T2b & $56(23.9)$ \\
T3 & $118(50.4)$ \\
Nodal stage & $56(23.9)$ \\
N0 & \\
N1 & $17(7.3)$ \\
N2 & $137(58.5)$ \\
Cancer stage, TNM ${ }^{c}$ classification & $80(34.2)$ \\
II & \\
III & $123(50.6)$ \\
Type of gastrectomy & $120(49.4)$ \\
Total & \\
Distal & $93(39.7)$ \\
Th & $141(60.3)$
\end{tabular}

${ }^{a)} \mathrm{T}$, the extent of the primary tumor; ${ }^{\mathrm{b})} \mathrm{N}$, the absence or presence and extent of regional lymph node metastasis; ${ }^{\mathrm{c}}{ }^{\mathrm{T}}$ The TNM system is an expression of the anatomic extent of disease and is based on the assessment of T, N, M. M-The absence or presence of distant metastasis a week after gastrectomy as a standard procedure. During their stay in hospital, post-operative therapeutic diet accompanied by oral nutritional supplement (ONS) were provided. At the time of discharge, the patients were also advised to use ONS at home.

\section{Evaluation of nutritional status-related indices}

Results of nutritional status-related assessments are shown in Table 2. The average weight loss between the first admission for operation and starting point of the first cycle of the chemotherapy was $6.8 \%$. There were 36 patients (15.4\%) who lost $\geq 10 \%$ of their body weight. At the starting point of the chemotherapy, 27 patients $(11.5 \%)$ were underweight $\left(\mathrm{BMI}<18.5 \mathrm{~kg} / \mathrm{m}^{2}\right)$ and $14.5 \%$ of the patients were hypoalbuminemia $(<3.5 \mathrm{~g} / \mathrm{dL})$. Patients with PG-SGA category B were 59.0 and $27.8 \%$ of the patients exhibited PG-SGA score $\geq 9$ which indicates the need for aggressive nutrition intervention. Assessment results from NRI showed that $63.2 \%$ of the patients were moderate malnutrition while $3.0 \%$ of the patients belong to the severe malnutrition group.

Table 2 Nutritional status-related indices of the patients

\begin{tabular}{|c|c|}
\hline Index & No $(\%)(n=234)$ \\
\hline \multicolumn{2}{|l|}{ Weight loss (\%) } \\
\hline mean & 6.8 \\
\hline$<10 \%$ weight loss & $198(84.6)$ \\
\hline$\geq 10 \%$ & $36(15.4)$ \\
\hline \multicolumn{2}{|c|}{ Body mass index $\left(\mathrm{kg} / \mathrm{m}^{2}\right)$} \\
\hline mean & 21.86 \\
\hline$<18.5$ & $27(11.5)$ \\
\hline$\geq 18.5$ & $207(88.5)$ \\
\hline \multicolumn{2}{|l|}{ Albumin (g/dL) } \\
\hline mean & 3.71 \\
\hline$<3.5$ & $34(14.5)$ \\
\hline$\geq 3.5$ & $200(85.5)$ \\
\hline \multicolumn{2}{|l|}{ PG-SGA category } \\
\hline A & $96(41.0)$ \\
\hline B & $138(59.0)$ \\
\hline \multicolumn{2}{|l|}{ PG-SGA score } \\
\hline mean & 7.42 \\
\hline$<9$ & $169(72.2)$ \\
\hline$\geq 9$ & $65(27.8)$ \\
\hline \multicolumn{2}{|l|}{ NRI } \\
\hline mean & 95.2 \\
\hline$>97.5$ & 79 (33.8) \\
\hline $83.5-97.5$ & $148(63.2)$ \\
\hline$<83.5$ & $7(3.0)$ \\
\hline
\end{tabular}

PG-SGA Patient-Generated Subjective Global Assessment, NRI Nutritional Risk Index 


\section{Treatment-associated adverse events}

Table 3 indicates hematological and non-hematological adverse events reported in study subjects. Ninety-four percent of the subjects experienced hematological adverse events with $>$ grade 1 , and $16.2 \%$ had adverse events greater than grade 3 . The most common adverse event among those over grade 3 was neutropenia; 32 (13.6\%) and 7 (3\%) patients exhibited neutropenia and anemia, respectively. Non-hematological adverse events with $>$ grade 1 were present in $95.7 \%$ of the patients. The patients who experienced non-hematological adverse events greater than grade 3 were $16.7 \%$. The most common adverse event was diarrhea followed by abdominal pain. There was no cancer-related death. Seventy percent of the patients finished their therapy as it was planned. However, $27.4 \%$ of the patients were subjected to drug dose reduction and $13.6 \%$ of the patients needed to cease the therapy (data not shown). We found that age was positively associated with completion of chemotherapy (OR 1.04; 95\% CI 1.01-1.07, $p=0.003$; Additional file 1: Table S1). In addition, there was a positive relationship of total gastrectomy (OR 2.20; 95\% CI 1.15$4.23, p=0.018$ ) and hypoalbuminemia (OR 2.25; 95\% CI 1.01-5.04, $p=0.048$ ) with delayed chemotherapy
(Additional file 1: Table S1). We did not observe any significant relationship of PG-SGA or NRI with either completion or delay of chemotherapy. The common adverse events such as diarrhea and abdominal pain were not significantly associated with PG-SGA or NRI (Additional file 2: Table S2).

Binary logistic regression analyses indicated that female sex, hypoalbuminemia, and BMI were associated with adverse event greater than grade 3 (Table 4). Multivariate analyses showed the hypoalbuminemia (OR 2.45; 95\% CI 1.02-5.89, $p=0.045$ ) and female sex (OR 2.39; 95\% CI 1.15-4.96, $p=0.020)$ were significant risk factors while BMI was a protective factor (OR 0.86; 95\% CI 0.74-0.99, $p=0.035$ ) (Table 4). Clinical and nutritional assessment indices related to non-hematological adverse events are shown in Table 5. Age was associated with adverse events greater than grade 3. Multivariate analyses indicated that age was a significant risk factor (OR 1.06; 95\% CI 1.03-1.10, $p<0.001$ ) (Table 5). There was no significant relationship of PG-SGA and NRI with hematological or non-hematological adverse events (Tables 4 and 5).

Binary logistic regression analyses between neutropenia and clinical or nutritional variables suggested that

Table 3 Hematological and non-hematological adverse events $(n=234)$

\begin{tabular}{|c|c|c|c|c|c|c|c|}
\hline \multirow[t]{2}{*}{ Events } & & \multicolumn{6}{|c|}{ Grade of chemotherapy toxicity (No (\%)) } \\
\hline & & Grade 0 & Grade 1 & Grade 2 & Grade 3 & Grade 4 & Grade $3+4(\%)$ \\
\hline \multirow[t]{6}{*}{ Hematological adverse events } & Anemia & $29(12.4)$ & $153(65.4)$ & $45(19.2)$ & $7(3.0)$ & - & 3 \\
\hline & Neutropenia & $94(40.2)$ & $41(17.5)$ & $67(28.6)$ & $31(13.2)$ & $1(0.4)$ & 13.6 \\
\hline & Thrombocytopenia & $150(64.1)$ & $73(31.2)$ & $10(4.3)$ & $1(0.4)$ & - & 0.4 \\
\hline & Febrile neutropenia & 233(99.6) & - & - & $1(0.4)$ & - & 0.4 \\
\hline & Leucopenia & $125(53.4)$ & $86(36.8)$ & $22(9.4)$ & $1(0.4)$ & - & 0.4 \\
\hline & Total & $14(6.0)$ & $95(40.6)$ & $87(37.2)$ & $37(15.8)$ & $1(0.4)$ & 16.2 \\
\hline \multirow[t]{15}{*}{ Non-hematological adverse events } & Anorexia & $142(60.7)$ & $61(26.1)$ & $28(12.0)$ & $3(1.3)$ & - & 1.3 \\
\hline & Nausea & $165(70.5)$ & $51(21.8)$ & $17(7.3)$ & $1(0.4)$ & - & 0.4 \\
\hline & Vomiting & 206(88.0) & $16(6.8)$ & $11(4.7)$ & $1(0.4)$ & - & 0.4 \\
\hline & Diarrhea & $119(50.9)$ & $58(24.8)$ & $43(18.4)$ & $14(6.0)$ & - & 6 \\
\hline & Constipation & 213(91.0) & $19(8.1)$ & $2(0.9)$ & - & - & 0 \\
\hline & Abdominal pain & 183(78.2) & $31(13.2)$ & $10(4.3)$ & $10(4.3)$ & - & 4.3 \\
\hline & Stomatitis & $191(81.6)$ & 26(11.1) & $15(6.4)$ & $2(0.9)$ & - & 0.9 \\
\hline & Hand-foot syndrome & $200(85.5)$ & $27(11.5)$ & $6(2.6)$ & $1(0.4)$ & - & 0.4 \\
\hline & Fatigue & 194(82.9) & $35(15.0)$ & $4(1.7)$ & $1(0.4)$ & - & 0.4 \\
\hline & Hyperpigmentation & $183(78.2)$ & $47(20.1)$ & $3(1.3)$ & $1(0.4)$ & - & 0.4 \\
\hline & Rash & 215(91.9) & $14(6.0)$ & $3(1.3)$ & $2(0.9)$ & - & 0.8 \\
\hline & Elevated AST/ALT level & $149(63.7)$ & $77(32.9)$ & $5(2.1)$ & $3(1.3)$ & - & 1.3 \\
\hline & Elevated bilirubin level & $89(38.0)$ & $99(42.3)$ & $43(18.4)$ & $3(1.3)$ & - & 1.3 \\
\hline & Elevated creatinine level & 230(98.3) & $4(1.7)$ & - & - & - & 0 \\
\hline & Total & $10(4.3)$ & $99(23.1)$ & $86(36.8)$ & $39(16.7)$ & - & 16.7 \\
\hline
\end{tabular}


Table 4 Multivariable logistic regression analysis of risk factors for hematological adverse events

\begin{tabular}{|c|c|c|c|c|c|c|c|}
\hline \multirow[t]{2}{*}{ Variables } & & \multirow{2}{*}{$\begin{array}{l}\text { Grade } 0-2 \\
(N=196)\end{array}$} & \multirow{2}{*}{$\begin{array}{l}\text { Grade } 3-4 \\
(N=38)\end{array}$} & \multicolumn{2}{|l|}{ Univariate } & \multicolumn{2}{|l|}{ Multivariate $^{\text {a) }}$} \\
\hline & & & & OR $(95 \% \mathrm{Cl})$ & $p$ & OR $(95 \% \mathrm{Cl})$ & $p$ \\
\hline Age (y) & & & & $0.99(0.96-1.02)$ & 0.472 & & \\
\hline \multirow[t]{2}{*}{ Sex } & Female & $66(75.9 \%)$ & $21(24.1 \%)$ & $2.43(1.20-4.92)$ & 0.013 & $2.39(1.15-4.96)$ & 0.020 \\
\hline & Male & $130(88.4 \%)$ & $17(11.6 \%)$ & 1.00 & & 1.00 & \\
\hline \multirow[t]{2}{*}{ Operation type } & Total & $72(77.4 \%)$ & $21(22.6 \%)$ & $2.13(1.05-4.29)$ & 0.035 & $1.79(0.86-3.74)$ & 0.119 \\
\hline & Distal & $124(87.9 \%)$ & $17(12.1 \%)$ & 1.00 & & 1.00 & \\
\hline \multirow[t]{2}{*}{ Creatinine clearance $\left.(\mathrm{mL} / \mathrm{min})^{\mathrm{b}}\right)$} & $\geq 60$ & $165(83.8 \%)$ & $32(16.2 \%)$ & 1.00 & 0.997 & & \\
\hline & $<60$ & $31(83.8 \%)$ & $6(16.2 \%)$ & $0.99(0.39-2.59)$ & & & \\
\hline \multirow[t]{2}{*}{ Albumin (g/dL) } & $<3.5$ & $24(70.6 \%)$ & $10(29.4 \%)$ & $2.56(1.11-5.92)$ & 0.028 & $2.45(1.02-5.89)$ & 0.045 \\
\hline & $\geq 3.5$ & $172(86.0 \%)$ & $28(14.0 \%)$ & 1.00 & & 1.00 & \\
\hline BMI $\left(\mathrm{kg} / \mathrm{m}^{2}\right)$ & & & & $0.83(0.72-0.95)$ & 0.007 & $0.86(0.74-0.99)$ & 0.035 \\
\hline \multirow[t]{2}{*}{ PG-SGA category } & A & $78(81.3 \%)$ & $18(18.8 \%)$ & 1.00 & 0.078 & & \\
\hline & B & 118 (85.5\%) & $20(14.5 \%)$ & $0.44(0.17-1.09)$ & & & \\
\hline PG-SGA score & & & & $0.88(0.76-1.01)$ & 0.083 & & \\
\hline Weight loss (\%) & & & & $0.97(0.88-1.07)$ & 0.558 & & \\
\hline NRI & & & & $0.96(0.89-1.02)$ & 0.163 & & \\
\hline
\end{tabular}

${ }^{a)}$ Covariates used in multivariate analyses included sex, operation type, albumin, and BMl; ${ }^{\text {b) }}$ Creatinine clearance was calculated using the Cockroft-Gault formula; BMI Body Mass Index, PG-SGA Patient-Generated Subjective Global Assessment, NRI Nutritional Risk Index

female sex, total gastrectomy, and hypoalbuminemia were risk factors for neutropenia (Table 6). Multivariate analyses indicated that female sex (OR 2.24; 95\% CI $1.03-4.87, p=0.043$ ), total gastrectomy (OR 2.71; 95\% CI 1.23-5.97, $p=0.013$ ) and hypoalbuminemia (OR 2.61; 95\% CI 1.01-6.54, $p=0.045$ ) were independent risk factors (Table 6). No significant relationship of PG-SGA or NRI with neutropenia was observed (Table 6).

\section{Discussion}

This study was conducted to identify sensitive nutritional status-related indices associated with the appearance of chemotherapy-induced adverse events in patients who underwent gastrectomy. S-1 complementary chemotherapy is a part of standard treatment protocol for stage 2 and 3A stomach cancer patients. Gastrectomy patients receiving S-1 therapy can start oral feeding within 6 weeks

Table 5 Multivariable logistic regression analysis of risk factors for non-hematological adverse events

\begin{tabular}{|c|c|c|c|c|c|c|c|}
\hline \multirow[t]{2}{*}{ Variables } & & \multirow{2}{*}{$\begin{array}{l}\text { Grade } 0-2 \\
(N=195)\end{array}$} & \multirow{2}{*}{$\begin{array}{l}\text { Grade } 3-4 \\
(N=39)\end{array}$} & \multicolumn{2}{|l|}{ Univariate } & \multicolumn{2}{|l|}{ Multivariate $^{\text {a) }}$} \\
\hline & & & & OR $(95 \% \mathrm{Cl})$ & $p$ & OR $(95 \% \mathrm{Cl})$ & $p$ \\
\hline Age (y) & & & & $0.83(0.72-0.95)$ & 0.007 & $1.06(1.03-1.10)$ & 0.000 \\
\hline \multirow[t]{2}{*}{ Sex } & $\mathrm{F}$ & $72(82.8 \%)$ & $15(17.2 \%)$ & $1.07(0.53-2.17)$ & 0.856 & & \\
\hline & M & $123(83.7 \%)$ & $24(24.55)$ & 1.00 & & & \\
\hline \multirow[t]{2}{*}{ Operation type } & Total & $78(83.9 \%)$ & $15(16.1 \%)$ & $0.94(0.46-1.90)$ & 0.858 & & \\
\hline & Distal & $117(83.05)$ & $24(17.0 \%)$ & 1.00 & & & \\
\hline \multirow[t]{2}{*}{ Creatinine clearance $(\mathrm{mL} / \mathrm{min})^{\mathrm{b}}{ }^{\text {b }}$} & $\geq 60$ & $170(86.3 \%)$ & $27(13.7 \%)$ & 1.00 & 0.007 & 1.00 & 0.370 \\
\hline & $<60$ & $25(67.6 \%)$ & $12(32.4 \%)$ & $3.02(1.36-6.72)$ & & $1.52(0.61-3.79)$ & \\
\hline \multirow[t]{2}{*}{ Albumin (g/dL) } & $<3.5$ & $25(73.5 \%)$ & $9(26.5 \%)$ & $2.04(0.87-4.04)$ & 0.102 & & \\
\hline & $\geq 3.5$ & $170(85.0 \%)$ & $30(15.0 \%)$ & 1.00 & & & \\
\hline BMI $\left(\mathrm{kg} / \mathrm{m}^{2}\right)$ & & & & $0.97(0.85-1.10)$ & 0.581 & & \\
\hline \multirow[t]{2}{*}{ PG-SGA category } & A & $84(87.5 \%)$ & $12(12.5 \%)$ & 1.00 & 0.157 & & \\
\hline & B & $111(80.4 \%)$ & $27(19.6 \%)$ & $1.70(0.82-3.56)$ & & & \\
\hline PG-SGA score & & & & $1.03(0.91-1.17)$ & 0.658 & & \\
\hline Weight loss (\%) & & & & $0.96(0.86-1.07)$ & 0.442 & & \\
\hline NRI & & & & $0.95(0.89-1.01)$ & 0.083 & & \\
\hline
\end{tabular}

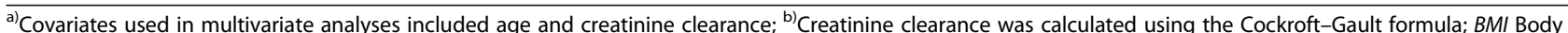
Mass Index, PG-SGA Patient-Generated Subjective Global Assessment, NRI Nutritional Risk Index 
Table 6 Multivariable logistic regression analysis of risk factors for neutropenia

\begin{tabular}{|c|c|c|c|c|c|c|c|}
\hline \multirow[t]{2}{*}{ Variables } & & \multirow{2}{*}{$\begin{array}{l}\text { Grade } 0-2 \\
(N=202)\end{array}$} & \multirow{2}{*}{$\begin{array}{l}\text { Grade } 3-4 \\
(N=32)\end{array}$} & \multicolumn{2}{|l|}{ Univariate } & \multicolumn{2}{|l|}{ Multivariate $^{\text {a) }}$} \\
\hline & & & & OR $(95 \% \mathrm{Cl})$ & $p$ & OR $(95 \% \mathrm{Cl})$ & $p$ \\
\hline Age (y) & & & & $0.99(0.42-2.33)$ & 0.554 & & \\
\hline \multirow[t]{2}{*}{ Sex } & $\mathrm{F}$ & $70(80.5 \%)$ & $17(19.5 \%)$ & $2.14(1.01-4.54)$ & 0.048 & $2.24(1.03-4.87)$ & 0.043 \\
\hline & M & $132(89.8 \%)$ & $15(10.2 \%)$ & 1.00 & & 1.00 & \\
\hline \multirow[t]{2}{*}{ Operation type } & Total & $73(78.5 \%)$ & $20(21.5 \%)$ & $2.95(1.36-6.37)$ & 0.006 & $2.71(1.23-5.97)$ & 0.013 \\
\hline & Distal & $129(91.5 \%)$ & $12(8.5 \%)$ & 1.00 & & 1.00 & \\
\hline \multirow[t]{2}{*}{ Creatinine clearance $(\mathrm{mL} / \mathrm{min})^{\mathrm{b}}{ }^{\mathrm{b}}$} & $\geq 60$ & $170(86.3 \%)$ & $27(13.7 \%)$ & 1.00 & 0.975 & & \\
\hline & $<60$ & $32(86.5 \%)$ & $5(13.5 \%)$ & $0.98(0.35-2.75)$ & & & \\
\hline \multirow[t]{2}{*}{ Albumin (g/dL) } & $<3.5$ & $25(73.5 \%)$ & $9(26.5 \%)$ & $2.77(1.15-6.66)$ & 0.023 & $2.61(1.01-6.54)$ & 0.040 \\
\hline & $\geq 3.5$ & $177(88.5 \%)$ & $23(11.5 \%)$ & 1.00 & & 1.00 & \\
\hline $\mathrm{BMI}\left(\mathrm{kg} / \mathrm{m}^{2}\right)$ & & & & $0.87(0.75-1.00)$ & 0.054 & & \\
\hline \multirow[t]{2}{*}{ PG-SGA category } & A & $80(83.3 \%)$ & $16(16.7 \%)$ & 1.00 & 0.106 & & \\
\hline & B & $122(88.4 \%)$ & $16(11.6 \%)$ & $0.44(0.16-1.19)$ & & & \\
\hline PG-SGA score & & & & $0.87(0.75-1.02)$ & 0.080 & & \\
\hline Weight loss (\%) & & & & $1.11(0.92-1.12)$ & 0.728 & & \\
\hline$N R I$ & & & & $0.95(0.89-1.01)$ & 0.110 & & \\
\hline
\end{tabular}

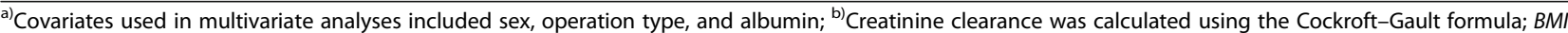
Body Mass Index, PG-SGA Patient-Generated Subjective Global Assessment, NRI Nutritional Risk Index

while the transition period from nutritional support to oral feeding is normally 6 months in these patients experiencing a great deal of weight loss. Few studies have provided evidences showing association between pretreatment nutritional status indices and treatmentassociated adverse events which possibly delay the completion of treatment and the recovery.

The rates of adverse events observed in our subjects under S-1 therapy were similar to those reported in the previous study with S-1 gastrectomy patients [12]. Most frequent hematological and non-hematological adverse events were neutropenia and diarrhea. Seventy \% of 234 patients completed the therapy according to the therapy protocol, and $27.4 \%$ of the patients were subjected to dosage reduction and $12.6 \%$ discontinued the therapy indicating at least one third of the gastrectomy patients did not tolerate S-1 therapy. Study results clearly suggested that patients with hypoalbuminemia and low BMI are highly susceptible to hematological adverse events and neutropenia was specifically frequent among patients with hypoalbuminemia. S-1 therapy usually starts 3 to 6 weeks after gastrectomy operation when operation-related fluctuation of other biochemical indices become stable and there is less chance of albumin being affected by operation itself. Therefore, the circulating albumin concentration can partly predict the compliance with adjuvant chemotherapy.

A meta-analysis study has suggested that serum albumin is a reliable index to predict cancer survival [10]. Moreover, hypoalbuminemia was reported as an independent prognostic marker of cancer fatality [15], and prognostic nutritional index calculated based on serum albumin and lymphocytes was reported as a prognostic marker in stomach cancer patients [16].

The increased synthesis of IL- $1 \beta$, IL- 6 and TNF- $\alpha$ is known to suppress liver synthesis of albumin, and the extent of reduction is related to disease severity $[17,18]$. The increased cytokine concentration is a hallmark of cancer cachexia accelerating tumor-associated tissue wasting and anorexia [19] and thus, decreases in albumin concentration may well reflect cancer cachexia. Given that other physiological factors including liver cirrhosis, nephritic syndrome, catabolic status, blood dilution, and decreased removal rate of lymphocytes can also induce changes in serum albumin concentration [20], hypoalbuminemia as an accurate index of nutritional status in cancer patients has been criticized [21]. Other studies have proposed that there is an increase in vascular permeability of albumin accelerating albumin flux towards extravascular compartment [22] and the disruption of blood albumin homeostasis due to an increase in albumin degradation [23].

Despite the importance of nutritional status of patients receiving cancer treatment, a limited number of studies evaluated the association between nutritional status and other related indices. A previous study reported that SGA and hypoalbuminemia $(\leq 3.1 \mathrm{~g} / \mathrm{dL})$ were associated with chemotherapy-induced side effects in lung cancer patients treated with paclitaxel and cisplatin [24]. However, covariates were not accounted in their analyses, and there was no significant association for side effects over grade 3 . Also, it was not clear whether hypoalbuminemia 
was associated with albumin-binding characteristic of paclitaxel. Severe malnutrition assessed by NRI was shown to increase the adverse events and reduce the survival rate in metastasized colon cancer patients [25]. Especially, hypoalbuminemia and inflammatory status are shown to increase hematological adverse events. Another study suggested that higher PG-SGA score increased patients' hospitalization [26]. These studies used one or two indices to predict nutritional status. Also, in most of the studies, the number of patients was less than 100 including those with high severity. The present study used stomach cancer patients with grade 2 and 3A tumors using the same treatment protocol to minimize variables possibly affecting the occurrence of adverse events. We also compared a few different assessment tools to evaluate nutritional status. Our study results clearly show that hypoalbuminemia is a sensitive index to predict chemotherapy-associated side effects including neutropenia, the most frequently occurring hematological side effect. However, no significant association was observed for albumin with non-hematological adverse event. A recent review have indicated that nutritional status determined by PG-SGA was associated with nausea and vomiting in a consistent manner although the authors mentioned that non-hematological adverse events such as nausea and vomiting possess subjective nature [27]. To secure the reliability and reduce the variability of medical records on non-hematological adverse events, only those recorded by internal medicine specialists sharing identical diagnostic standards were used.

In this study, PG-SGA did not show a significant association with either hematological or non-hematological adverse events. A most presumable reason for this null association is a lack of sensitivity represented by PGSGA. Patients in the present study are those who are stable and in the course of transition to oral feeding after gastrectomy. Therefore, nutritional status could be overestimated through PG-SGA score. We also evaluated \% weight change (weight loss) between the initial hospitalization and shortly before starting chemotherapy as a nutritional status index. Many of the patients have already lost their weight at the initial hospitalization, and this may explain the lack of sensitivity by \% weight loss in chemotherapy-induced adverse events. Recently, Consensus Statement from the European Society of Clinical Nutrition and Metabolism (ESPEN) suggested to use either BMI less than $18.5 \mathrm{~kg} / \mathrm{m}^{2}$ or the combination of weight loss together with either a low BMI or a low fat fess mass index as diagnostic criteria for malnutrition [28]. In the meantime, the American Society for Parenteral and Enteral Nutrition (ASPEN) suggested that two or more out of six characteristics including insufficient energy intake, weight loss, loss of muscle mass, loss of subcutanueou fat, localized of generalized fluid accumulation, diminished functional status as measured by hand-grip strength can be used to diagnose adult malnutrition [29]. Nutritional assessment based on these suggestions may better predict possible adverse events in these patients. Neutropenia was the second most frequently occurring adverse event. Female, total gastrectomy, and lower albumin concentration were significantly associated with neutropenia. A recent multicenter randomized controlled trial indicated that capecitabine plus oxaliplatin adjuvant therapy for D2 gastrectomy exhibited neutropenia in $60 \%$ of the enrolled subjects, and 3- year disease free survival was significantly higher in males but not in females indicating sex-specific treatment protocol may be required based on chemotherapy-induced adverse events [30].

Limitations of this study are as below. First, this is a retrospective study which may have pit-falls in the collected data. To minimize the limitation, we have included entire medical records written by internal medicine specialists during S-1 therapy. Secondly, the initial body weight used to determine \% weight change was the measurement after gastrectomy, and therefore, removed tissue weight was not calculated. Lastly, only $16 \%$ of the patients were reported to have side-effects, and this may cause a lack of sensitivity to PG-SGA score and NRI.

\section{Conclusions}

In conclusion, blood albumin concentration can be used as a marker of a successful completion of cancer chemotherapy before starting chemotherapeutic treatment. Findings of this study also suggest there is frequently used nutritional screening tools were unable to predict major chemotherapy-induced adverse events which suggest PG-SGA and \% weight loss may not be sensitive indices to predict treatment endurance in these patients. Further studies on standardized nutrition screening with a larger number of cancer patients with specific type of cancer may provide accurate diagnostic value of nutritional screening tools applicable to different clinical settings.

\section{Additional files}

Additional file 1: Table S1. Multivariable logistic regression analysis of risk factors for chemotherapy regimen. (DOCX $19 \mathrm{~kb}$ )

Additional file 2: Table S2. The relationships of PG-SGA and NRI with diarrhea and abdominal pain. (DOCX $12 \mathrm{~kb}$ )

Abbreviations

BMI: Body Mass Index; NRI: Nutrition Risk Index; PG-SGA: Patient-Generated Subjective Global Assessment

Acknowledgement

Not applicable. 


\section{Funding}

This research was supported by the High Value-added Food Technology Development Program (312006-3), the Ministry for Food, Agriculture, Forestry and Fisheries, Republic of Korea, the SRC program (Center for Food \& Nutritional Genomics: 2015R1A5A6001906) of the National Research Foundation of Korea (NRF) funded by the Ministry of Education, Science and Technology, and the NRF grant funded by the Korea government (MSIP) (No.2011-0030074).

\section{Availability of data and materials}

The dataset supporting the conclusions of this article cannot be shared to protect patients' confidentiality, but can be obtained upon reasonable request from the authors.

\section{Authors' contributions}

M-KS contributed to the conceptualization and design of the research and interpretation of the data; SHS drafted manuscript and contributed to the analysis and interpretation of the data; S-EK contributed to the interpretation of the data and critically revised the manuscript; Y-KK, B-YR, and M-HR contributed to the acquisition of the data; JHJ contributed to the acquisition and interpretation of the data; MY contributed to the interpretation of the data; JEL contributed to the analysis of the data; and Y-KK, B-YR, M-HR, SSK, and M-KS agreed to be fully accountable for ensuring the integrity and accuracy of the work. All authors have read and approved the final manuscript.

\section{Competing interests}

The authors declare that they have no competing interests.

\section{Consent for publication}

Not applicable.

\section{Ethics approval and consent to participate}

The study was approved by the Institutional Review Board of Asan Medical Center. The committee's reference number is 2012-0221. Individual consent was waived because this study was retrospective in design and based on database extracted records.

\section{Author details}

'Department of Food and Nutrition, Sookmyung Women's University, 100, Cheongpa-ro 47-gil, Yongsan-gu, Seoul 04310, South Korea. ${ }^{2}$ Department of Oncology, Asan Medical Center, University of Ulsan College of Medicine, Seoul 05505, South Korea. ${ }^{3}$ Department of Dietetics and Nutrition Services Team, Asan Medical Center, Seoul 05505, South Korea. ${ }^{4}$ Research Center for Cell Fate Control, College of Pharmacy, Sookmyung Women's University, Seoul 04310, Republic of Korea.

\section{Received: 8 March 2016 Accepted: 26 October 2016}

\section{Published online: 18 November 2016}

\section{References}

1. von Meyenfeldt M. Cancer-associated malnutrition: an introduction. Eur J Oncol Nurs. 2005;9 Suppl 2:S35-8.

2. La Torre M, Ziparo V, Nigri G, Cavallini M, Balducci G, Ramacciato G. Malnutrition and pancreatic surgery: prevalence and outcomes. J Surg Oncol. 2013;107(7):702-8.

3. Sanford DE, Sanford AM, Fields RC, Hawkins WG, Strasberg SM, Linehan DC. Severe nutritional risk predicts decreased long-term survival in geriatric patients undergoing pancreaticoduodenectomy for benign disease. J Am Coll Surg. 2014;219(6):1149-56.

4. Grant B, Byron J. Nutritional implications of chemoterapy. In: Elliot L Molseed LL, McCallum PD, editors. The clinical guide to oncology nutrition. 2nd ed. Chicago: American Dietetic Association; 2006.

5. Santarpia L, Contaldo F, Pasanisi F. Nutritional screening and early treatment of malnutrition in cancer patients. J Cachex Sarcopenia Muscle. 2011:2(1):27-35.

6. Salas S, Deville JL, Giorgi R, Pignon T, Bagarry D, Barrau K, Zanaret M Giovanni A, Bourgeois A, Favre R, et al. Nutritional factors as predictors of response to radio-chemotherapy and survival in unresectable squamous head and neck carcinoma. Radiother Oncol. 2008;87(2):195-200.

7. Cessot A, Hebuterne X Coriat R, Durand JP, Mir O, Mateus C, Cacheux W, Lemarie $E$, Michallet $M$, de Montreuil CB, et al. Defining the clinical condition of cancer patients: it is time to switch from performance status to nutritional status. Support Care Cancer. 2011;19(7):869-70.
8. Boleo-Tome C, Monteiro-Grillo I, Camilo M, Ravasco P. Validation of the Malnutrition Universal Screening Tool (MUST) in cancer. Br J Nutr. 2012; 108(2):343-8.

9. McCallum PD, Polisena CG. The clinical guide to oncology nutrition. 1st ed. Chicago: American Dietetic Association; 2000.

10. Gupta D, Lis CG, Vashi PG, Lammersfeld CA. Impact of improved nutritional status on survival in ovarian cancer. Support Care Cancer. 2010;18(3):373-81.

11. Marian M, Roberts S. Clinical nutrition for oncology patients. Sudbury: Jones \& Bartlett Learning; 2010

12. Sakuramoto S, Sasako M, Yamaguchi T, Kinoshita T, Fujii M, Nashimoto A, Furukawa H, Nakajima T, Ohashi Y, Imamura H, et al. Adjuvant chemotherapy for gastric cancer with S-1, an oral fluoropyrimidine. N Engl J Med. 2007; 357(18):1810-20.

13. Jeong JH, Ryu MH, Ryoo BY, Lee SS, Park I, Lee SH, Kim KC, Yook JH, Oh ST, Kim BS, et al. Safety and feasibility of adjuvant chemotherapy with S-1 for Korean patients with curatively resected advanced gastric cancer. Cancer Chemother Pharmacol. 2012;70(4):523-9.

14. Ikeda M, Furukawa H, Imamura H, Shimizu J, Ishida H, Masutani S, Tatsuta M, Kawasaki T, Satomi T. Pharmacokinetic study of S-1, a novel oral fluorouracil antitumor agent in animal model and in patients with impaired renal function. Cancer Chemother Pharmacol. 2002;50(1):25-32.

15. Di Fiore F, Lecleire S, Pop D, Rigal O, Hamidou H, Paillot B, Ducrotte P, Lerebours $E$, Michel $P$. Baseline nutritional status is predictive of response to treatment and survival in patients treated by definitive chemoradiotherapy for a locally advanced esophageal cancer. Am J Gastroenterol. 2007;102(11):2557-63.

16. Nozoe T, Ninomiya M, Maeda T, Matsukuma A, Nakashima H, Ezaki T. Prognostic nutritional index: a tool to predict the biological aggressiveness of gastric carcinoma. Surg Today. 2010;40(5):440-3.

17. McMillan DC, Watson WS, O'Gorman P, Preston T, Scott HR, McArdle CS. Albumin concentrations are primarily determined by the body cell mass and the systemic inflammatory response in cancer patients with weight loss. Nutr Cancer. 2001;39(2):210-3.

18. Barber MD, Ross JA, Fearon KC. Changes in nutritional, functional, and inflammatory markers in advanced pancreatic cancer. Nutr Cancer. 1999:35(2):106-10.

19. Suzuki H, Asakawa A, Amitani H, Nakamura N, Inui A. Cancer cachexiapathophysiology and management. J Gastroenterol. 2013:48(5):574-94.

20. Numeroso F, Barilli AL, Delsignore R. Prevalence and significance of hypoalbuminemia in an internal medicine department. Eur J Intern Med. 2008;19(8):587-91

21. Lis CG, Grutsch JF, Vashi PG, Lammersfeld CA. Is serum albumin an independent predictor of survival in patients with breast cancer? JPEN J Parenter Enteral Nutr. 2003;27(1):10-5.

22. Fleck A, Raines G, Hawker F, Trotter J, Wallace PI, Ledingham IM, Calman KC. Increased vascular permeability: a major cause of hypoalbuminaemia in disease and injury. Lancet. 1985:1(8432):781-4

23. Andersson C, Lonnroth C, Moldawer LL, Ternell M, Lundholm K. Increased degradation of albumin in cancer is not due to conformational or chemical modifications in the albumin molecule. J Surg Res. 1990;49(1):23-9.

24. Arrieta O, Michel Ortega RM, Villanueva-Rodriguez G, Serna-Thome MG, Flores-Estrada D, Diaz-Romero C, Rodriguez CM, Martinez L, Sanchez-Lara K. Association of nutritional status and serum albumin levels with development of toxicity in patients with advanced non-small cell lung cancer treated with paclitaxel-cisplatin chemotherapy: a prospective study. BMC Cancer. 2010:10:50

25. Barret M, Malka D, Aparicio T, Dalban C, Locher C, Sabate JM, Louafi S, Mansourbakht T, Bonnetain F, Attar A, et al. Nutritional status affects treatment tolerability and survival in metastatic colorectal cance patients: results of an AGEO prospective multicenter study. Oncology. 2011:81(5-6):395-402

26. Hill A, Kiss N, Hodgson B, Crowe TC, Walsh AD. Associations between nutritional status, weight loss, radiotherapy treatment toxicity and treatment outcomes in gastrointestinal cancer patients. Clin Nutr. 2011;30(1):92-8.

27. Marx W, Kiss N, McCarthy AL, McKavanagh D, Isenring L. Chemotherapyinduced nausea and vomiting: a narrative review to inform dietetics practice. J Acad Nutr Diet. 2016;116(5):819-27.

28. Cederholm T, Bosaeus I, Barazzoni R, Bauer J, Van Gossum A, Klek S, Muscaritoli M, Nyulasi I, Ockenga J, Schneider SM, et al. Diagnostic criteria for malnutrition - an ESPEN consensus statement. Clin Nutr. 2015;34(3):335-40.

29. White JV Guenter P, Jensen G, Malone A, Schofield M Consensus statement: Academy of Nutrition and Dietetics and American Society for 
Parenteral and Enteral Nutrition: characteristics recommended for the identification and documentation of adult malnutrition (undernutrition). JPEN J Parenter Enteral Nutr. 2012;36(3):275-83.

30. Bang YJ, Kim YW, Yang HK, Chung HC, Park YK, Lee KH, Lee KW, Kim YH, Noh SI, Cho JY, et al. Adjuvant capecitabine and oxaliplatin for gastric cancer after D2 gastrectomy (CLASSIC): a phase 3 open-label, randomised controlled trial. Lancet. 2012;379(9813):315-21.

Submit your next manuscript to BioMed Central and we will help you at every step:

- We accept pre-submission inquiries

- Our selector tool helps you to find the most relevant journal

- We provide round the clock customer support

- Convenient online submission

- Thorough peer review

- Inclusion in PubMed and all major indexing services

- Maximum visibility for your research

Submit your manuscript at www.biomedcentral.com/submit 